\title{
Teoría y práctica de administración y cobranza de rentas reales en Navarra (siglo XVIII)
}

\author{
Theory and practice of royal incomes administration and collection \\ in Navarre $\left(18^{\text {th }}\right.$ century) \\ SERGIO SOLBES FERRI \\ Universidad de Las Palmas de Gran Canaria
}

\begin{abstract}
RESUMEN
El artículo pretende reflexionar sobre los limitados avances que, en la práctica, se siguen de la introducción de las reformas hacendísticas borbónicas en la España del siglo XVIII, por medio del conocimiento de su aplicación en un territorio de privilegiada fiscalidad como es el reino de Navarra. Pretendemos profundizar en el conocimiento de unos programas reformadores, teóricamente desarrollados y con voluntad generalizadora, que terminan traducidos en modificaciones básicamente administrativas o de gobierno de las rentas reales, como testimonio de la inviabilidad de una reforma fiscal que no puede o no quiere transformar la esencia contributiva sobre la que se sustenta.
\end{abstract}

PALABRAS CLAVE: Hacienda, Administración, España, Navarra, siglo XVIII Códigos JEL: N43, N93, H71, H73

\section{ABSTRACT}

This paper talks about the restricted effects that the Borbonic reforms had in 18th century Spain through the knowledge of their application in a financial privileged region such as the kingdom of Navarre. We try to find out more about this experience with reform programs that they only brought administrative changes in the royal incomes government, proving that the financial reform is not effective unless the taxes bases were previously modified.

KEY WORDS: Public Treasury, Administration, Spain, Navarre, 18th century

JEL Codes: N43, N93, H71, H73 


\section{Introducción ${ }^{1}$}

$\mathrm{E}$ 1 rey necesita dinero. Siempre necesita dinero para sostener su administración y el ejercicio de la justicia, pero sobre todo para hacer frente a pagos de carácter militar, muy considerables incluso en tiempo de paz, pues el prestigio internacional de la Monarquía depende de ellos. Reducir el gasto es impensable, por lo que la solución pasa siempre por el aumento de los ingresos y el recurso al crédito o a expedientes extraordinarios, solución esta última llevada a tal extremo durante el siglo XVII que prácticamente queda agotada como opción, lastrando las finanzas del XVIII con el peso de los juros. Queda la alternativa de aumentar los ingresos incrementando la presión fiscal, algo factible siempre que se esté dispuesto a suprimir privilegios personales o territoriales, pero la Monarquía tampoco parece dispuesta a ello o no puede hacerlo sin alterar las bases políticas y sociales sobre las que se sustenta. Por eso, los ensayos renovadores que finalmente aplica la dinastía borbónica, con el propósito de sanear las finanzas públicas, no pueden pasar del intento de acrecentar los ingresos del Estado por medio de una serie de reajustes en la administración y gestión de los tributos tendentes a simplificar su recaudo, separar su gobierno de manos privadas y centralizar su control ${ }^{2}$.

El sistema tributario español se caracteriza, como el de todas las monarquías del Antiguo Régimen, por contar con una cantidad enorme de expedientes fiscales que en la práctica se pueden agrupar, y así lo harán en el XVIII, bajo tres sistemas impositivos: Rentas Provinciales, Rentas Generales y Rentas Estancadas ${ }^{3}$; unas fuentes de financiación pública que se traducen en contribuciones indirectas de modo casi general $^{4}$. A este esquema, que se aplica sin dificultad en la mayor parte de Castilla, se superpone el particular de los territorios forales, cuya privilegiada fiscalidad suele traducirse en la exención de contribuciones por rentas provinciales (compensado, en ocasiones, por Servicios de Cortes o Juntas Generales), junto a la posibilidad de que, tanto el producto de rentas generales como el de estancadas, sea destinado en todo o en parte a la financiación de sus haciendas privativas ${ }^{5}$. Por eso, la equiparación fiscal tras la guerra de Sucesión de la Corona de Aragón con la de Castilla se basa pre-

Quiero agradecer las críticas y comentarios de los evaluadores anónimos y del Consejo de Redacción de Investigaciones de Historia Económica.

2 Fontana (1980), pp. 15-31, Artola (1982), pp. 209-319, Zafra (1991), p. 20, o García-Cuenca (1991), pp. 59-64

3 Fontana (1980), pp. 15-29 y Artola (1982), pp. 279-294. La simplificación es quizá excesiva, pues no tiene en cuenta contribuciones eclesiásticas ni ingresos de Indias, entre otros, pero es imprescindible para nuestro objeto. Un conocimiento exhaustivo de todas las rentas que pertenecen al real Erario a mediados del XVIII en Pieper (1992), pp. 97-158 o Merino (1987).

Zafra (1991), García-Cuenca (1991), p. 64 y García-Zúñiga, Mugartegui y Torre (1991), pp. 81-83.

Bilbao (1984 y 1991), Bernabé Gil (1993) y, últimamente, Hernández (2003). 
cisamente en la supresión de haciendas forales, la absorción de su patrimonio y rentas por la Hacienda real y la imposición de contribuciones "equivalentes" a las rentas provinciales castellanas ${ }^{6}$. La ausencia de un derecho de conquista impide, sin embargo, que el mismo proceso pudiera darse en los territorios vasco-navarros, que sí apoyaron la causa de Felipe $V$, razón por la que mantuvieron durante el siglo XVIII un régimen hacendístico diferenciado, aunque no exento de reformas prácticas en relación con sus fórmulas contributivas, de recaudo y administración ${ }^{7}$.

Las más recientes publicaciones sobre los logros obtenidos durante el siglo XVIII en el terreno hacendístico y fiscal nos permiten aseverar la validez de los argumentos expuestos, pero también determinan la conveniencia de seguir reflexionando sobre este apartado de la Historia Económica, con el propósito de valorar por qué dichos cambios no sirvieron para evitar el rotundo fracaso en la adecuación de ingresos y gastos que provoca el inicio de la "crisis del Antiguo Régimen". En este contexto, han sido especialmente destacadas las últimas aportaciones sobre la particular fiscalidad de estos territorios privilegiados o exentos, en los que resulta sencillo comprender las dificultades que encuentra cualquier reforma gubernativa ${ }^{8}$. Por este motivo, me parece oportuno proceder a una nueva aproximación a la Hacienda real en Navarra, desde una perspectiva alejada, en este caso, de la evolución cronológica, de la personificación en la gestión de las rentas, del análisis de la presión fiscal soportada o del dato numérico 9 . Quisiera centrar mi análisis, por el contrario, en la realidad del gobierno y el alcance de las medidas administrativas aplicadas por la nueva dinastía, dentro de un contexto referido al conjunto de la Monarquía Hispánica y especialmente centrado en la primera mitad del siglo XVIII ${ }^{10}$, jugando además con la idea de Ripia y Gallard de que, en materia hacendística, no es lo mismo lo dispuesto por las leyes que la realidad práctica de su gobierno cotidiano.

6 Véase el planteamiento general de Kamen (1974), para el caso catalán, Fernández de Pinedo (1984) y para el caso valenciano, García Trobat (1999).

7 Para el caso vasco, véase Mugartegui (1990) o Fernández de Pinedo (1991). Para el caso navarro, Solbes (1999a), pp. 280-284, y García-Zúñiga (1993), pp. 307-334.

8 Es una de las conclusiones de Rey Castelao (2004), en su visión global sobre la evolución historiográfica de la fiscalidad en la España del Antiguo Régimen. Agradezco a la autora la posibilidad del conocimiento del texto previo a su publicación y me remito al mismo para cualquier consulta bibliográfica más sistematizada.

9 Estudios clásicos sobre su estructura de ingresos y gastos en Artola (1978) y Salcedo (1981); más recientes, García-Zúñiga (1993), Solbes (1996 y 1999a) y Hernández Escayola (2001); sobre la presión fiscal soportada, comparada con la de los restantes territorios de la Monarquía, puede consultarse García-Zuñiga, Mugartegui y Torre (1991); los efectos del régimen fiscal privilegiado sobre la economía navarra, en Azcona (1996), Astigarraga (1996) o Torre y García-Zúñiga (1998); en cuanto a valores, la cuestión está básicamente resuelta, con los usuales matices, en García-Zúñiga (1994).

10

La trascendencia principal de las reformas de tipo administrativo-fiscal introducidas durante la primera mitad del siglo XVIII ha sido destacada últimamente por González Enciso (2003), p. 47. 


\section{Planteamiento fiscal heredado por los Borbones en Navarra}

La Monarquía puede subvenir sus gastos en este reino mediante recursos procedentes de tres expedientes tradicionales, como son, los rendimientos derivados del Patrimonio real, Servicios de Cortes y renta de Tablas o Aduanas. Por su parte, la Hacienda foral, creada en 1642, se nutre de los ingresos generados por la venta de productos estancados y algún porcentaje que consigue detraer, tanto de los rendimientos aduaneros, como del Servicio de Cortes ${ }^{11}$. Esta estructura fiscal, válida para los siglos XVI y XVII, se modifica necesariamente con la enajenación completa del regio patrimonio en la primera mitad del XVII (como en el conjunto de la Monarquía) y cuando el estanco del Tabaco se transforma de hecho en renta real en el año 1717. Así pues, obviando el patrimonio real por ineficaz para nuestro análisis, los tres conceptos fiscales sobre los que vamos a reflexionar en el presente estudio serán: unos Servicios de Cortes que generan ingresos con destino a cargas militares, ocupando el espacio permitido por la exención de rentas provinciales; la renta de Aduanas, real y no foral, de la que se obtienen fondos con los que paliar gastos administrativos y que se puede relacionar sin ambages con el sistema de rentas generales; y, desde 1717, la renta del Tabaco, inserta en el ámbito de las rentas estancadas exigidas en Navarra.

\subsection{El Servicio o donativo de Cortes Generales ${ }^{12}$}

Es la concesión que los navarros ofrecen al monarca en dinero (aunque también puede adoptar la fórmula de donativo de hombres de guerra) ${ }^{13}$ cuando son convocados en Cortes Generales, lo que sucede de forma regular hasta mediados del XVII y sin regla fija desde entonces. Su característica definitoria, y germen de toda controversia, es la voluntariedad teórica de su concesión, tanto en cuanto a la cantidad ofrecida como respecto del sistema de recaudo escogido. La realidad es que, a diferencia de lo de que sucede en Castilla y Aragón, las Cortes navarras se reunieron durante todo el Antiguo Régimen y los donativos otorgados mantuvieron siempre esa condición teórica de voluntarios por lo que, estrictamente, deben ser considerados real servicio y no renta real, aunque la distinción carezca de efectos prácticos en el XVIII ${ }^{14}$.

11 Sobre la Hacienda foral navarra, véase García-Zúñiga (1992). Sus principales expedientes, junto con su fecha de creación, son el estanco del tabaco (1642), impuesto de extracción de lanas (1642), impuesto sobre sentencias (1645), retenciones sobre el Servicio de Cortes (1654) y estanco del chocolate (1678).

12 Las leyes de concesión de los donativos navarros entre 1512 y 1828 se encuentran reunidas en Vázquez de Prada y otros (1993); un análisis más profundo de los otorgados entre 1700 y 1765, en Solbes (1999a), pp. 44-57; una valoración general en García-Zúñiga (1993), pp. 310-314.

13 Como ocurre en el siglo XVIII con el Servicio de 1705, en el contexto de la guerra de Sucesión, compuesto por tres regimientos de seiscientos hombres cada uno. Véase Solbes (1999a), pp. 103-104.

$14 \quad$ Zafra (1991), p. 61. 
El recaudo del dinero se efectúa tradicionalmente a través de dos expedientes: cuarteles y alcabalas. El cuartel (abonado cuatro veces al año) es, en origen, un impuesto directo sobre la propiedad que toma la tasación de la riqueza territorial como referencia para el reparto de las cargas entre los vecinos contribuyentes. La alcabala o "veintena" es similar al tributo castellano medieval y se trata de una imposición indirecta sobre el tráfico comercial que debe abonar el vendedor, pudiendo repercutir su valor sobre el consumidor, con las particularidades de que el porcentaje aplicado en Navarra no es del 10 sino del 5 por 100 (de ahí el término veintena) y de que nunca perdió su función como medio de pago de los donativos. La práctica recaudatoria se encargaría de transformar el planteamiento descrito pues, tras la conquista, quedó establecido un reparto fijo que asignaba a cada municipio la cantidad que debía contribuir por cuartel, cuyo recaudo quedaba al cargo de unas justicias municipales que pronto recurrieron a la práctica del encabezamiento para situar los pagos sobre fondos comunes del lugar ${ }^{15}$. La alcabala se convirtió también en una cantidad fija para cada población cuya suma, según un reparto distinto basado en este caso en la estimación media de los intercambios, determinaba una "tanda de alcabala", de cuyo abono quedaban asimismo encargadas unas justicias municipales que recurrieron al mismo proceso de encabezamiento y, por lo tanto, a los mismos fondos para su dotación. Así, en la práctica, el tribunal real de la Cámara de Comptos ${ }^{16}$ comunicaba simultáneamente las cantidades asignadas en ambos repartos a ciudades, villas, lugares, valles y céndeas del reino para requerirlas al pago en los plazos establecidos. Estas acudían, primeramente, a recursos del municipio provenientes de propios o comunales; en caso de no ser suficientes, procedían a aplicar una fiscalidad indirecta sobre los vecinos por medio de sisas sobre artículos de primera necesidad; y, sólo en último término, a la fórmula original de reparto directo entre los propietarios (cuarteles) o el comercio (alcabalas), lo que casi nunca sucedía ${ }^{17}$.

El valor fijo de los expedientes determinó que el modo habitual de incrementar la concesión fuera el de aumentar el número de cuarteles o tandas de alcabala otorgados. Así, a finales del siglo XVI, eran cuarenta los cuarteles y cuatro las tandas

15 El encabezamiento es la obligación mancomunada por parte de un colectivo o población de atender al pago del cupo que se les asigna y de cuya recaudación responden todos los vecinos de forma solidaria, pudiéndose otorgar posterior refacción a los inicialmente exentos (Zafra, 1991, pp. 93-96).

16 Uno de los tres tribunales reales de Navarra (junto al Consejo Real y la Real Corte) encargado del gobierno y conservación de los intereses reales, así como de administrar justicia en causas de fraude (con apelación al Consejo Real), organizar el recaudo de los expedientes y distribuir los fondos mediante órdenes de pago y libranzas giradas sobre la tesorería general de Navarra. Sobre esta cuestión véase Salcedo (1981).

17 Gordo (1993), p. 314, considera que sólo los concejos de poca extensión y escasos medios (abundantes en la mitad septentrional del reino) optarían por el reparto vecinal, porque aquéllos cuyos bienes de propios fuesen importantes y su economía más desenvuelta, utilizaban sus rentas para efectuar los pagos, ampliando sus fuentes de ingreso mediante sisas. 
de alcabala ofrecidos por cada año transcurrido entre dos reuniones, cuyo valor entero rondaba los 600.000 reales de vellón anuales. A partir de aquí, los rebates sobre los pagos (exenciones, gracias y privilegios, personales o municipales) reducían un 20 por 100 esa cantidad, mientras los gastos del recaudo y de celebración de Cortes rebajaban dicha cantidad en otro 10 por 100. El resto, el valor líquido, llegaría a la tesorería general de Pamplona desde donde, con permiso de la Cámara de Comptos, podía atenderse el capítulo de un gasto fundamentalmente militar como dijimos, manteniendo el principio preceptivo de que todos los ingresos fiscales obtenidos en Navarra debían ser utilizados dentro de sus fronteras. El problema es que, previamente, había que hacer frente a una serie de antiguas afectaciones y mercedes contraídas por la Monarquía en favor de los notables del reino, que se llevaban nada menos que un 40 por 100 del valor líquido. De modo que, finalmente, el dinero disponible quedaba reducido a poco más de 250.000 reales de vellón anuales.

Desde principios del siglo XVII, la Monarquía tuvo que recurrir al crédito o a la transferencia de ingresos obtenidos en otros territorios para mantener operativas las defensas de Navarra, mientras los naturales iban quedando gradualmente exentos del pago de nuevas contribuciones castellanas como los cientos o los millones. No puede causar extrañeza que la corona descuidara sus funciones y perdiera interés en la convocatoria regular del congreso navarro, como en los otros reinos forales, pero lo que no se ha destacado convenientemente es que, con esta opción, resultaban igualmente perjudicadas las instituciones forales y las élites navarras, que perdían capacidad de intervención legislativa a cambio del ahorro de unas contribuciones no excesivamente onerosas de las que estaban probablemente exentas, si no interesadas. No hubo, por tanto, oposición sino interés mutuo en la introducción durante las Cortes de 1652 de una concesión adicional por donativo, un Servicio Extraordinario, que convertiría al sistema ya descrito en el Servicio Ordinario.

El Extraordinario consiste en la entrega al monarca de una cantidad indeterminada de dinero libre de consignaciones preestablecidas (ni rebates, ni gastos de Cortes y con una única retención del 4 por 100 para gastos del recaudo) que queda a su completa disposición (ni pago de mercedes, ni obligación de gastar el dinero en Navarra). Su recaudo se efectúa por cuenta de un titular distinto, como es la diputación foral, y por medio de un expediente diferente, el reparto por fuegos, que establece el pago de un cupo determinado a cada localidad según el número de vecinos que figura en apeos realizados por las instituciones forales ${ }^{18}$. En la práctica, la diputación

18 Contribución directa, pero regresiva, por no tomar en consideración la situación económica de cada contribuyente. Tanto en el reino de Valencia, como en el principado de Cataluña, se recurrió en los siglos XVI y XVII a una figura impositiva parecida, como son las tachas, para completar el recaudo de los donativos (Bernabé, 1993, p. 20). 
(no la Cámara de Comptos) remite circular a cada lugar indicando cantidad y plazos asignados para remitir el dinero a su secretario pero, a partir de aquí, se altera de nuevo la esencia del sistema porque los municipios (alcaldes o jurados convertidos por la diputación en agentes fiscales) disponen de la opción de pagar con fondos procedentes de sus propias rentas o repartir a cada vecino la cantidad estipulada, siendo voluntad expresa de las instituciones forales que los caudales procediesen prioritariamente de propios, rentas y expedientes municipales y que, sólo en caso de ser insuficientes, se recurriera al reparto. El impuesto perdía así su condición de imposición directa, para detraerse de los mismos fondos utilizados para el pago del Ordinario ${ }^{19}$.

El nuevo expediente encubre, por lo tanto, en la práctica contributiva una simple revisión de los encabezamientos de cuarteles y alcabalas, con supresión de rebates por los pagos y una mejor disponibilidad de efectivo al monarca, que coincide con la filosofía que presidió la aplicación en Castilla de los cuatro unos por ciento entre 1639 y 1664 . La principal novedad es entonces de tipo administrativo, pues el expediente sería recaudado por medio del reino y no del rey, lo que guarda relación, tanto con la creación del Servicio de Millones castellano, como con la dotación de funciones a las haciendas forales aragonesas. El monarca ganaba rentabilidad económica mientras el reino aseguraba la convocatoria regular de los tres Estados e incrementaba su capacidad de autogestión. Durante la segunda mitad del siglo XVII, ambas partes fueron perdiendo interés en el Ordinario (admitiendo, para contentar a los antiguos beneficiarios, el pago de una única anualidad por reunión) para centrar sus expectativas en el Extraordinario.

\subsection{La renta de Tablas o Aduanas ${ }^{20}$}

La corona dispone en Navarra, desde el siglo XIII y como derecho de regalía, de la posibilidad de recaudar unos derechos aduaneros que se traducen normalmente en impuestos indirectos girados ad valorem sobre el movimiento de importación-exportación de géneros entre el reino y territorios limítrofes. El control de esta fuente de ingreso y la gestión de los caudales percibidos pertenece a la Real Hacienda en exclusiva, como sabemos. Estos derechos aduaneros, exigidos en una serie de oficinas dispuestas en las fronteras y otros puntos estratégicos del territorio denominadas tablas (término que, por extensión, da nombre a la renta en su conjunto), se rigen por el siguiente planteamiento teórico: por derechos de exportación o "saca" se exige el

\footnotetext{
19 Aunque Hernández Escayola (2001), pp. 194-195, muestra la existencia de repartos realmente aplicados en determinadas poblaciones navarras.

20 Solbes (1999a), pp. 57-75, y García-Zúñiga (1993), pp. 320-324.
} 
veinte-uno sobre el precio del producto (5 por 100) y por derechos de importación o "peajes" el treinta-uno (3,33 por 100), quedando exentos de esta última contribución los productos de primera necesidad introducidos por naturales ${ }^{21}$. Esta baja presión fiscal viene acompañada, además, por una serie de exenciones y privilegios que acaban dando a Navarra una configuración muy próxima al libre comercio: sobre los derechos de exportación se aplicaron progresivas reducciones destinadas a no interferir la salida de los excedentes productivos del reino (lana, vino y productos de las ferrerías), mientras la exención de derechos de entrada para productos de primera necesidad fue extendiéndose hasta alcanzar el rango de norma general aplicada sobre cualquier género importado por naturales. Es decir, los comerciantes navarros estaban prácticamente excluidos de los pagos y sólo los extranjeros abonaban unos reducidos derechos arancelarios sobre el tránsito por el territorio foral de productos destinados a la reexportación y, aún en este caso, disponían de alternativas para esquivar la imposición: la legal, pero costosa, de obtener naturaleza de navarro; la más sencilla, pero fraudulenta, de "encabezar" las mercancías bajo nombre de naturales; y, la más habitual, la negociación directa con los gestores de la renta para alcanzar acuerdos de reducción de las tasas a cambio de asegurar los pagos, estimular el tránsito y reducir el interés económico del contrabando ${ }^{22}$. En definitiva, ningún producto abonaba en la práctica los derechos teóricos que hemos mencionado, fuera del género que fuese y lo transportara quien lo transportara.

La Corona dispone de los dos sistemas propios de las monarquías del Antiguo Régimen para aplicar su capacidad fiscal sobre el comercio: arrendamiento y administración directa.

a) Arrendamiento. Este mecanismo financiero, el más utilizado durante los siglos XVI, XVII y primera mitad del XVIII, permite, mediante la cesión del gobierno de la renta, la disposición anticipada de unos fondos seguros. El problema es que suele devenir en dejación de facultades reales en manos privadas, pues la Hacienda real, previo pago de fianzas y caudales adelantados, se desprende del usufructo de las rentas y de la facultad recaudatoria ${ }^{23}$. La persona o grupo de personas que obtenía en

21 Una presión fiscal inferior a la castellana que, en opinión de García-Cuenca (1983), p. 238, que cita a Gallardo, podríamos situar en torno al 15 por 100 del valor de los géneros al menos hasta 1782 .

22 Las rebajas de gravámenes estaban expresamente permitidas, tanto en España como en otros países. Según Hernández Escayola (2001), p. 44, se alcanzaban, además, acuerdos tales como eximir de derechos de saca a cambio de cobrar íntegros los derechos de entrada, perdonar partidas a los que proporcionaban más ingresos, etc.

23 Zafra (1991), pp. 91-93. Azcona (1996) destaca que la mayor parte de los arrendadores eran los propios comerciantes del reino organizados para tal fin. Hernández Escayola (2001), pp. 51-59 concluye que se trató siempre de grupos organizados en compañías constituidas al efecto, cuyo aliciente no parece que fuera la obtención del producto de la recaudación, sino las actividades lícitas o ilícitas que podían acompañar al manejo de la renta. 
pública subasta la cesión del manejo de la renta ${ }^{24}$, actuaba posteriormente sin sometimiento alguno al control de los tribunales y sin obligación de presentar cuentas ante instancia alguna. La única preocupación de la Cámara de Comptos se centraba en verificar la entrega puntual en la tesorería general de las cantidades estipuladas en el contrato de arriendo o ejecutar las fianzas en caso de incumplimiento. Los arrendadores solían proceder a la elección de un administrador al que encargaban del gobierno de la renta, así como del nombramiento del resto de empleados a los que debían instruir en su labor y abonar el salario establecido por la costumbre.

b) Administración directa. La alternativa al arriendo pasa por encargar el recaudo de los ingresos aduaneros al propio tribunal de Comptos, que procedería a escoger a $\mathrm{su}$ propio administrador general (normalmente el tesorero general) y al resto de empleados, quedando de cuenta suya el pago de los salarios. Esto sólo sucede, en principio, ante la ausencia de ofertas válidas para el arriendo, pues el lógico incremento de los gastos de gestión reduce de forma significativa los valores líquidos e imposibilita la anticipación de recursos que permite el sistema de arriendos. Sólo desde finales del siglo XVII comienza a estudiarse la posibilidad de recurrir al uso continuado de este sistema, considerando que la reducción de sus ventajas económicas podía verse compensada por una gestión más ajustada de la renta y de menor compadreo entre los propios comerciantes. La planta de empleados dispuesta en estos casos solía estar constituida por cerca de cien hombres, organizados en torno a cuatro apartados: empleados de administración en la aduana general de Pamplona; un empleado por puesto aduanero (entre 70 y 80); cuatro sobrecogedores encargados de recoger y traer a Pamplona los caudales de aduanas alejadas; y los miembros del resguardo, menos de una docena de hombres en los inicios del siglo XVIII, que cuentan con la indispensable colaboración del Ejército en funciones de vigilancia de los pasos del Pirineo (los soldados de los puertos). Así, de la misma manera que el donativo convertía a alcaldes y jurados municipales en agentes fiscales, se integraba al Ejército en el resguardo aduanero.

Bajo cualquiera de las dos fórmulas de gestión referidas, los valores líquidos obtenidos sirven para el pago de los salarios de empleados públicos (virrey, regente, tribunales de justicia, etc.), mercedes con calidad de salario y juros derivados de los censos tomados por la corona durante la segunda mitad del siglo XVII. Así, la realidad práctica referida a este apartado se resume en la captación de los derechos derivados de la aplicación de una fiscalidad enormemente privilegiada, destinada a cubrir un capítulo del gasto que rondaba los 450.000 reales de vellón anuales ${ }^{25}$. Por eso, la mejor solución para que el reino autofinanciase sus costes administrativos

24 La organización de las subastas a remate de candela puede ampliarse en Hernández Escayola (2001), pp. 28-29.

25 Un análisis pormenorizado de las distintas partidas del gasto situado sobre la renta de Aduanas, en Solbes (1996), pp. 149-150. 
seguía siendo el recurso a la firma de un contrato de arriendo con los comerciantes interesados en los tránsitos a través de Navarra por un valor cercano a la referida cantidad.

\section{Las reformas borbónicas aplicadas sobre los expedientes fiscales de Navarra}

Un patrimonio agotado, un donativo que cubre parte de los gastos militares y una renta de aduanas que, si la negociación del arriendo lo permite, sostiene a duras penas el aparato administrativo del reino. Esta es la situación de las finanzas públicas que hereda Felipe V en Navarra. A partir de aquí, pueden distinguirse dos importantes ofensivas reformadoras que tienen el objeto de superar el planteamiento descrito, que podemos situar entre 1716-1726 y 1740-1749, y que están separadas por tres períodos de menor actividad. Los años del conflicto sucesorio se caracterizan, en realidad, por el recurso a vías extraordinarias para incrementar ingresos y reducir el gasto; por eso, la primera ofensiva se inicia al término del conflicto, cuando Alberoni y sus sucesores tratan de extender al territorio vasco-navarro el proyecto de Orry basado en la exigencia de una contribución anual y regular, supresión de aduanas internas y captación de estancos a favor de la Real Hacienda. Su fracaso es relativo pues, aunque no logra imponerse en toda su amplitud, introduce una serie de modificaciones administrativas que serán hábilmente utilizadas por Patiño, desde 1726, con el fin de alcanzar objetivos básicos de rentabilidad; el decreto de suspensión de pagos de 1739 abre paso a una nueva etapa de cambios, personificada por Ensenada y que tiene como principal objeto la aplicación del sistema de administración directa sobre las rentas de la corona. A mediados de la centuria rige en Navarra un sistema fiscal, teóricamente análogo al heredado de los Austrias, pero muy distinto en la práctica como veremos.

\subsection{El Servicio de Cortes}

Pronto se evidencia el deseo del gobierno de Felipe V de simplificar el recaudo de los donativos navarros, centralizar su control y aumentar su rentabilidad. Sin embargo, la primera novedad guarda relación exclusiva con los apuros financieros derivados del conflicto sucesorio: la creación de una tesorería de guerra y la aplicación del real valimiento sobre el producto de las rentas reales entre 1706 y 1716. Esta decisión no afecta al recaudo de los tres donativos otorgados por los navarros durante esta etapa pero sí al destino de su producto, al anunciar la Monarquía su intención de no acudir al pago de las obligaciones tradicionalmente consignadas sobre ellos. La fórmula del 
valimiento ofrecía entonces al monarca la posibilidad de disponer libremente del dinero recaudado por el Servicio Ordinario, lo que hacía innecesaria la existencia de un reparto por fuegos, muy denostado por el nuevo gobierno por quedar fuera de su control. La reacción del reino en defensa de sus intereses fue rápida, dotando al Extraordinario en 1709 de una condición a la que en principio no podía aspirar el Ordinario, como es la de ofrecer todo su producto adelantado de contado a la tesorería real, financiado mediante sus propias rentas, para recaudarlo posteriormente ${ }^{26}$.

El posterior proyecto de reforma fiscal de Alberoni estaba basado, siguiendo la filosofía que había llevado a la ordenación de las rentas provinciales castellanas ${ }^{27}$ y al establecimiento de los equivalentes aragoneses ${ }^{28}$, en la necesidad del establecimiento de una contribución anual y regular que hiciera frente a los gastos militares propios de cada territorio que, en este caso, tendría que lograrse respetando la legislación foral, sin recurso a la vía coercitiva, y sobre la base de los antiguos cuarteles y alcabalas. Lo utópico de la propuesta y su fracaso último nos lo demuestra el hecho de que los donativos navarros mantuvieran su condición de voluntarios y no regulares durante todo el siglo, lo que supeditaba su recaudo a una concesión previa de las Cortes. No obstante, en el congreso de 1716-1717, se introdujeron dos importantes novedades al respecto: en primer lugar, el expediente de cuarteles y alcabalas quedaba definitivamente liberado de la atención a rebates y partidas obligatorias del gasto con la aceptación de una especie de "valimiento perpetuo", asumiendo la principal virtud de un Extraordinario cuya concesión quedaba en suspenso; en segundo lugar, se introdujo una nueva fórmula de recaudo denominada expediente de mercaderías por estar basada en la exigencia a los mercaderes naturales de los mismos derechos de importación que a los extranjeros (lo que ponía fin a su ancestral exención), gestionado por una Hacienda foral que adelantaría a la tesorería sus futuros rendimientos ${ }^{29}$. Parecen decisiones de algún modo contrapuestas que obedecen a distintas consideraciones: con la primera, el monarca trataba de recuperar su control sobre los donativos mientras que, con la segunda, los navarros trataban de evitar la aplicación de disposiciones gubernativas

26 Esta solución también fue utilizada en la Corona de Aragón y en las Provincias Vascas (Bilbao, 1984, p. 77, y 1991, p. 54; Mugartegui, 1990, pp. 192-193). La diputación utilizaría para este fin caudales propios de la Hacienda foral, fondos del Depósito General (dinero de particulares y comunidades para gastos de fundaciones, mayorazgos y obras pías) y préstamos de instituciones eclesiásticas o comerciantes bajo garantía de las rentas forales. Hernández Escayola (2001), p. 195 señala que ya se había recurrido anteriormente a la fórmula del adelantamiento, pero no se incluye como condición expresa del donativo hasta 1709 (véanse las leyes de concesión en Vázquez de Prada y otros, 1993).

27 El decreto de 26-XII-1713 establece que, desde 1714, todos los ramos de Rentas Provinciales debían correr unidos, designándose un único arrendatario por provincia (Zafra, 2001, p. 105 y Angulo Teja, 2002, pp. 482-484). Véanse al respecto el estudio clásico de Kamen (1974) o el más reciente de García Trobat (1999).

La diputación optó siempre por la administración directa del expediente, encomendándola al administrador o arrendatario de aduanas (más información en Hernández Escayola, 2001, pp. 126-129). 
más rigurosas sobre el ámbito de su tradicional libertad comercial, algo que no lograron pues, como veremos, al año siguiente quedó dispuesta la supresión de las fronteras privativas del reino y su traslado al Pirineo.

La reposición de las antiguas aduanas en 1723, unida a los escasos rendimientos propiciados por el nuevo donativo, obligó a proceder a una revisión del mismo en las Cortes de 1724-1726, sobre unos criterios de rentabilidad que se imponen a cualquier propósito de reforma fiscal. Iba a quedar consolidada entonces una nueva fórmula de recaudo de los Servicios de Navarra que resume todas las modificaciones introducidas hasta entonces: la corona renunciaba de forma explícita a la conversión de los cuarteles y alcabalas en una contribución regular, pero el expediente quedaba completamente liberado de sus antiguas obligaciones en cuanto al gasto; reaparece el reparto por fuegos, con los apeos actualizados e incluidas las novedades relativas a la entrega de contado de su producto por parte de la diputación ${ }^{30}$; y se consolida la exacción de un expediente de mercancías vigente hasta la obtención de un montante, previamente adelantado por la diputación, que muy pronto se convertiría en una imposición permanente conocida como nuevo impuesto ${ }^{31}$.

En la Corte no quedaron demasiado satisfechos con las novedades alcanzadas pues, ni Patiño, ni Campillo, reunieron al congreso de los navarros durante sus respectivas etapas al frente del gobierno: el monarca quedaba huérfano de sus recursos económicos pero las instituciones del reino no tenían la posibilidad de ejercer su capacidad legislativa. No obstante, en el largo plazo, los apuros financieros de la monarquía y la posibilidad de ingresos rápidos que ofrecía la fórmula diseñada tenían necesariamente que jugar a favor de un reino que, en 1743, recibió orden de proceder a una nueva reunión. Ensenada asumía directamente el tipo de donativo preestablecido para tratar de obtener de él las mayores ventajas pecuniarias posibles, renunciando a la transformación de las bases fiscales y al control gubernativo de los expedientes de recaudo. A partir de esta concesión y sobre la base del recaudo de los tres expedientes referidos (cuarteles y alcabalas, reparto por fuegos y nuevo impuesto), el real Erario obtuvo importantes cantidades de dinero en cada una de las cinco ocasiones en que volvieron a reunirse los navarros antes de finalizar el siglo, fijadas de antemano y con un buen porcentaje entregado de contado, con reducciones y gastos mínimos para la Hacienda real. En 1765-1766 se introdujo incluso una última posibilidad de mejora: la entrega de contado por parte de la diputación del porcentaje

$30 \quad$ El nuevo apeo de 1727 (33.800 fuegos) sustituiría al de 1677 (30.430 fuegos).

31 Experimentaría sucesivas modificaciones en su aplicación: en 1724-1726 se reduce la tasa aplicada sobre los naturales hasta la mitad de los derechos aduaneros abonados por extranjeros; en 1744 se arregla según el 1 por 100 del valor de los productos e incluye en su recaudo a los mercaderes extranjeros residentes en Navarra; en 1780-1781 ese 1 por 100 se aplicaría indiscriminadamente sobre cualquier tipo de comercio o comerciante (Solbes, 1999a, p. 198, y 1996, pp. 885-886). 
correspondiente a cuarteles y alcabalas que le sería posteriormente reintegrado por los empleados reales encargados de su recaudo ${ }^{32}$. El gobierno se consolaba del fracaso de su reforma fiscal con un incremento importante de la rentabilidad y la disponibilidad de los fondos del donativo.

La evolución del donativo de Cortes de Navarra se ajusta perfectamente al planteamiento descrito en el inicio del estudio: el fracaso de un inicial propósito de modificación de su esencia contributiva, en línea con el resto del país, le permite conservar características propias y privilegiadas, pero no quedar situado al margen de modificaciones administrativas beneficiosas para la corona. Estas mejoras se producen a costa de la salud de las finanzas de una Hacienda foral obligada a realizar importantes desembolsos puntuales que, debido a la propia naturaleza de los expedientes de recaudo, trasladaría al mundo del comercio (obligado a financiar parte de las entregas de contado) y sobre todo a las haciendas municipales (obligadas, a su vez, al recurso al crédito para adelantar los pagos debidos) ${ }^{33}$.

\subsection{La renta de Aduanas (1 $1^{\text {a }}$ etapa)}

Las aduanas de Navarra fueron gobernadas por administración directa entre 17001727, con excepción del arriendo de Juan de Lastiri (trienio 1704-1706) y el tiempo del traslado aduanero (1718-1722) ${ }^{34}$; entre 1728 y 1748 se retornó al sistema de arriendos con la firma de siete contratos trienales sucesivos ${ }^{35}$ hasta que, en 1749 , se impuso de modo definitivo la administración directa de la renta integrada dentro del sistema de rentas generales ${ }^{36}$.

32 Para un conocimiento más profundo de las características de los donativos otorgados en la segunda mitad del siglo XVIII y primer tercio del XIX, véanse Rodríguez Garraza (1974), pp. 133-145, 205-227 y 267-270, y Río Aldaz (1985), pp. 337-385, y sobre todo (1992), pp. 5-27.

La Hacienda foral recurre progresivamente a los hombres de negocios para lograr el dinero que precisa para cumplir con sus obligaciones. Hernández Escayola (2001), pp. 214-216 explica que hubo que imponerles dicha obligación, pues el interés aplicado no era suficientemente atractivo para ellos. Sobre la delicada situación de las haciendas municipales en la segunda mitad del XVIII, véase Torre (1993). Hernández Escayola (2001), pp. 30-32 considera que, al menos durante la etapa 1707-1716, la Cámara de Comptos no hubiera podido arrendar la renta, aún deseándolo, por falta de candidatos.

Esta etapa se caracteriza por el arriendo de la renta en manos de la familia de comerciantes navarros Iñíguez de Beortegui hasta que, en 1746, el grupo perdió el control en favor de Joaquín de Iturbide (Solbes, 1999a, p. 192).

36 El esquema coincide, a grandes rasgos pero no al detalle, con el aplicado en el contexto general de la Monarquía: desde 1717 se generaliza en España el sistema de administración directa, pero se retorna al sistema de arriendos a partir de 1726 con objeto de reducir gastos (Artola, 1982, p. 285); García-Cuenca (1983), p. 240 prefiere la fecha de 1734 para hablar de la vuelta generalizada a este sistema. Sobre los efectos de la suspensión de pagos y la consecuente apuesta por la aplicación de la administración directa, véase Fernández Albadalejo (1977), p. 76. 
El propósito inicial de Felipe $\mathrm{V}$ con respecto a la renta de Tablas navarra es muy claro y pasaba decididamente por su supresión, igual que todas las fronteras interiores de España, y su traslado a la frontera pirenaica. No obstante, mientras no pudiera adoptarse esa solución extrema, la corona trataría de reducir al menos la libertad comercial de los naturales, de centralizar la gestión de la renta, integrar el territorio dentro del mercado nacional y, sobre todo, reducir al máximo la introducción fraudulenta de productos franceses en el mercado castellano. La principal novedad de los años del conflicto sucesorio sería la aplicación del conocido valimiento sobre el producto de la renta, la retención de un porcentaje sobre el pago de salarios de empleados y, lo más llamativo, el nombramiento por Comptos de un antiguo arrendador para el puesto de administrador general (Lastiri, entre 1707 y 1713), dotado con facultades para el ejercicio de su cargo muy similares a las propias de los casos de arriendo aunque, en este caso, a cambio de un salario. Entre 1714-1718 y 1723-1726 Comptos volvió, en cambio, a situar al habitual tesorero real al frente de la administración aunque conservando un amplio margen de actuación. Lo que pretendo señalar es que, en definitiva, el gobierno práctico de la renta mediante la administración directa a través de Comptos no debía ser muy distinto al empleado durante el tiempo de los arriendos, siendo comunes en ambos casos los acuerdos por tránsito de mercancías y permitiendo la completa confusión entre caudales públicos y privados $^{37}$. Hernández Escayola sospecha incluso que Lastiri controló la renta durante todo el primer cuarto del siglo, fuera bajo la fórmula de arrendamiento, de administración o a través de hombres de paja interpuestos ${ }^{38}$. En consecuencia, el propósito de la corona no se limitaba tan sólo a la sustitución de la fórmula de arriendo por la administración directa sino que pretendía también relevar al tribunal de Comptos de la dirección de la renta, dentro de un proceso que puede insertarse en un contexto nacional de traspaso de funciones hacia las distintas Superintendencias de Hacienda ${ }^{39}$.

El traslado aduanero dispuesto por Alberoni (abril de 1718-diciembre de 1722) supuso el logro de todos los objetivos anteriormente referidos ${ }^{40}$. Pero es muy importante tener en cuenta que, ya antes del traslado, se habían adoptado medidas que

37 Los administradores podían utilizar los ingresos de la renta en sus negocios del mismo modo que debían suplir en ocasiones de sus propios fondos el dinero necesario para efectuar pagos consignados, una práctica habitual en todos los cargos hacendísticos durante el Antiguo Régimen (Hernández Escayola, 2001, p. 107). Hernández Escayola (2001), pp. 104-105.

Zafra (1991), p. 53.

El traslado aduanero fue aprobado por la Real Orden de 31 de agosto de 1717, pero en Navarra no se hizo efectivo hasta el 20 de abril de 1718. Sobre la ordenación aduanera aplicada, un análisis más detallado de las causas de su fracaso y del proceso de reposición de la Tablas de Navarra, véase Solbes (1999a), pp. 15052,157 y $170-178$. 
autolimitaban la libertad comercial de los navarros por lo que, pese a la frustración del traslado, en 1723 no se iba a regresar de ningún modo a la situación de partida. De este modo, en 1709 había quedado dispuesto el registro obligatorio de mercancías en tránsito en manos de naturales ${ }^{41}$; en 1713 fue publicado un arancel particular (complemento del Arancel General castellano de 1709) que establecía una contribución fija del 3 por 100 sobre las mercancías en tránsito; y en las Cortes de 1716-1717 se introdujo, como sabemos, el expediente de mercancías que ponía fin a la exención de derechos de entrada por parte de los naturales. La posterior supresión de las aduanas privativas representaba la culminación de este proceso y la desaparición de cualquier sombra de particularismo: dependencia directa de la Superintendencia de Rentas Generales, gestión bajo el cargo del Intendente General en lugar de los tribunales de Navarra; exacción de derechos propios del arancel castellano de 1709; integración en el mercado nacional y mayor incidencia en la lucha contra el fraude. Finalmente, la supresión de la nueva planta de aduanas y la reaparición de la renta de Tablas en 1723 determina el retorno a planteamientos administrativos anteriormente descritos, con el tesorero Gayarre como administrador por cuenta de Comptos, pero confirmadas las restricciones a la libertad comercial de los naturales anteriores a 1718: en 1723 fue publicado un nuevo arancel (versión ampliada y mejorada del de 1713) sobre tributación de los géneros en tránsito; en las Cortes de 1724-1726 se dispuso por ley el registro obligatorio de los naturales y se consolidó, como sabemos, la vigencia del expediente de mercancías.

De modo que la renta retornaba al seno de la Cámara de Comptos, pero con la antigua libertad comercial de los naturales seriamente tocada. Como en el caso de los donativos, se había pretendido aplicar una reforma de alcance y, tras su fracaso, la corona se debía conformar con la aplicación de una serie de novedades administrativas que mejoraban su capacidad de gestión. El gobierno tampoco podía encontrarse completamente satisfecho con lo logrado, de ahí que perdiera interés por el sistema de gestión utilizado para el gobierno de una renta que se mantenía dependiente de Pamplona y no de Madrid, inclinándose finalmente por retomar las ventajas estrictamente pecuniarias que seguía ofreciendo el sistema de los arriendos. De hecho, entre 1728 y 1748 se firmaron contratos que alcanzaron y superaron los 450.000 reales de vellón que supone el coste de la administración real en Navarra cargado sobre esta renta ${ }^{42}$. Volveremos más tarde sobre esta cuestión.

\footnotetext{
41 En unas "tablas de registro" dispuestas en las principales rutas del reino (Pamplona, Estella y Lumbier), conservando su exención tributaria pero abonando derechos de registro (un real por carga).

42

Valores en Solbes (1999a), p. 193.
} 


\subsection{La renta o estanco del Tabaco desde $1717^{43}$}

El expediente de recaudo que más tardíamente recala bajo el control de la Hacienda real en Navarra es el que, quizá por la ausencia de antiguas tradiciones y privilegios en su gestión, va a tolerar a la postre una mayor capacidad de intervención gubernativa en el reino ${ }^{44}$.

Los estancos son regalías o derechos inherentes a la soberanía del monarca que suponen la prohibición del curso y venta libre de un producto determinado, que queda en consecuencia situado bajo el control monopolista de la corona, aunque ésta puede cederlo a quien desee ${ }^{45}$. Este recurso fiscal, de naturaleza indirecta por definición, fue especialmente utilizado en la España del siglo XVII, y el del tabaco, establecido en Castilla a finales de 1636, fue sin duda el monopolio de mayor proyección ${ }^{46}$. Los reinos aragoneses, las Provincias vascas y Navarra quedaron inicialmente excluidos de la aplicación del decreto pero, en las Cortes navarras de 1642, el rey Felipe IV dotó con el monopolio de su venta al por menor a la recién creada Hacienda foral. En 1652 quedó ampliado el ámbito de aplicación del estanco para abarcar asimismo el abastecimiento de los géneros y las ventas al por mayor. Durante la segunda mitad del siglo XVII fueron aumentando tanto los ingresos derivados del arrendamiento continuado de los derechos como el contrabando o las medidas de oposición al mismo adoptadas por las autoridades forales ${ }^{47}$.

El deseo de la nueva dinastía borbónica fue, sin duda, el de hacerse con un control inmediato y absoluto del estanco y de sus crecientes ingresos en todo el ámbito nacional, uniformizando y centralizando su gestión. La guerra retrasó en parte estos propósitos, aunque también los simplificó en el caso de los reinos aragoneses, donde la Hacienda real pudo arrebatar el monopolio a las correspondientes haciendas forales o municipales, conforme los considerados rebeldes se rendían a las tropas reales: Valencia y Aragón en 1707, Cataluña en 1714 y Mallorca en $1715^{48}$. La propiedad del estanco navarro por parte de su hacienda foral debía ser teóricamente respetada por la fidelidad mostrada pero aún así, en mayo de 1715, se firmaba el que sería último contrato de

43 El interés por la renta del Tabaco es antiguo, como demuestran los estudios de González Enciso (1988) o la recopilación de Rodríguez Gordillo (2002b), pero ha venido a reactivarse en los últimos años con Comín y Martín Aceña (1999) y, sobre todo, la actividad del Grupo de Estudios del Tabaco, al que pertenezco desde su creación, plasmada en González Enciso y Torres (eds.) (1999), Luxán, Solbes y Laforet (eds.) (2000) o GRETA (2002).

$44 \quad$ Solbes (1999b) y (2000).

45 Comín (1991), pp. 139-140.

46 Un estudio monográfico en Rodríguez Gordillo (2002a).

47 La diputación, que siempre recurrió a la vía del arriendo, fijaría los precios de venta. El arrendador nombraría los guardas del resguardo y establecería los puestos para la venta, mediante subarriendo o nombramiento de empleados a sueldo. Véase Solbes (1999b), pp. 319-324. 
arriendo por cuenta de la diputación ${ }^{49}$. Y es que la corona ya tenía diseñada una fórmula para hacerse con el control del monopolio navarro, sugerida por la Cámara de Castilla, que fue presentada en el congreso navarro de 1716-1717: el arriendo perpetuo de la renta por la Hacienda real bajo las condiciones y precios del momento presente (87.529 reales de vellón anuales), manteniendo la Hacienda foral la propiedad teórica del estanco. El congreso navarro tuvo que admitir la propuesta, por ser rigurosamente legal, procurando convertir la cesión de perpetua en temporal para, siguiendo el estilo de los donativos, hacer necesaria su renovación periódica. En cualquier caso, la Hacienda real se hacía de facto con el control del estanco del Tabaco en Navarra a cambio del abono puntual de la cantidad mencionada en la tesorería del reino ${ }^{50}$.

El período inicial de aplicación de la nueva fórmula es muy impreciso, pues el inmediato traslado de las aduanas se confunde con las medidas adoptadas en 1717. El arriendo del estanco adquiere verdadera trascendencia con la reposición aduanera de 1723, pues su gestión se mantiene entonces dependiente de la Superintendencia del Tabaco, ofreciendo a la corona mayores posibilidades de intervención en el gobierno en Navarra o de oposición al contrabando que cualquier otro expediente. Según Instrucción Real de finales de 1722, se divide el territorio foral en partidos administrativos bajo el cargo de empleados públicos, cuyos poderes les sitúan en muchos casos por encima de justicias municipales y empleados aduaneros, mientras se incrementa hasta cincuenta el número de guardas para formar un cinturón defensivo junto con tablajeros, guardas de aduanas, soldados de los puertos más los guardas de las fronteras de Aragón y Castilla ${ }^{51}$. El gobierno de Grimaldo admitía la posibilidad de que el incremento del gasto superase el nivel de ingresos por venta de tabacos en Navarra, pero daba por bueno el déficit si se compensaba con los beneficios del estanco en territorios limítrofes, por reducción del contrabando, y con los resultados de la renta de Tablas. Las Cortes de 1724-1726 ratificaron los cambios introducidos y renovaron el contrato de cesión con asombrosa facilidad, convirtiendo a Navarra en una provincia administrativa más en el ámbito del estanco general, con su control administrativo y económico transferido a Madrid, gestionada bajo la fórmula de administración directa, abastecida desde las fábricas de Sevilla con tabacos que debía expender a precios dictaminados por el gobierno central y con empleados reales encargados de su resguardo. La función de la Hacienda foral, en este caso, se limitaba a recordar al monarca la necesidad de renovar los contratos de cesión y a percibir los inmutables 87.529 reales de vellón anuales.

\footnotetext{
49 Hernández Escayola (2001), pp. 81-82 estima que este último arriendo ya estaba controlado por el monarca, para comprobar de primera mano cuál era el estado de la renta antes de modificar el orden establecido. Solbes (1999b), pp. 325-331.

Instrucción Real de VIII/1722 al administrador Jarquiés (Solbes, 1999b, pp. 331-335).
} 
La implantación de este sistema, uniforme y centralizado, coincidirá con su aplicación en toda la Monarquía, dentro de un proceso que se inicia con la Real Cédula de 9/4/1701 y que culmina con el decreto de Universal Administración de $1730^{52}$. El reino de Navarra se considera, por tanto, una administración provincial más en el contexto del estanco general para el abastecimiento, distribución y venta de los géneros. La tercena o almacén de Pamplona sería abastecida desde Sevilla vía Madrid para atender el suministro de las administraciones particulares situadas en cabeceras comarcales, que se hacían cargo, a su vez, de la demanda de poblaciones menores. El tabaco sería expendido al por mayor en los almacenes y al por menor en estanquillos anexos o en puntos de venta a la décima (bajo el cargo de un comisionista que recibe el 10 por 100 del valor de las ventas) localizados en tabernas, carnicerías, abacerías, etc., mediante un sistema de "obligación" que garantizaba el beneficio de la renta. La renta daría ocupación a unos cincuenta empleados asalariados más setecientos puntos de venta comisionada, de modo que el comercio minorista se constituía, en este caso, en convidado de piedra para el recaudo de los ingresos del estanco. El recorrido del dinero es inverso al expresado partiendo desde estos puntos de venta (sometidos a continuadas visitas de inspección) hasta alcanzar la Tesorería General de Madrid, con informe anual del administrador provincial remitido a la Dirección General de Rentas ${ }^{53}$.

Resulta difícil entender por qué, tras haber alcanzado todas sus pretensiones, decidió Campillo reintegrar la gestión del estanco a la Hacienda foral en mayo de 1742, que la retendría en su poder durante dos años, hasta que Ensenada ordenó en abril de 1744 retornar al sistema de cesión por arriendo ${ }^{54}$. La explicación debe residir en la escasa rentabilidad mostrada por el estanco navarro y en la existencia de una fórmula alternativa de gestión que ejemplificaba el caso vasco ${ }^{55}$. En las Provincias Exentas no había sido implantando el estanco y Patiño había sancionado la libre introducción y comercio de tabaco para consumo de sus naturales a cambio de quedar terminantemente prohibida su posterior reexportación. En Navarra se había adoptado una fórmula que asumía el coste del traslado de la vigilancia fronteriza a las proximidades de Francia y las Provincias, pero hubiera sido perfectamente posible aplicar la fórmula vasca y, de hecho, existen indicios de que Patiño contempló

\footnotetext{
52 Real decreto 20/12/1730 e Instrucciones de 9/8/1731 y 10/8/1731 aplicado a partir de septiembre de 1731; existe una posterior Instrucción para organización de las funciones de sus empleados de 26/1/1740. Véase Escobedo (2004), pp. 363-430.

53 Para ampliar las cuestiones relativas al gobierno, abastecimiento y venta de tabacos en Navarra, véase Solbes (2000), pp. 250-259.

54 Reintegración de la renta a la diputación foral por la Real Cédula de 22/4/1742 y retorno al sistema de arriendo a la Hacienda real por Real Orden de 27/10/1743. Véase Solbes (1999b), pp. 347-349.

55 El estanco de la renta del Tabaco como tal, no se verificaría en las Provincias Exentas hasta 1878. Véase Angulo Morales (1999).
} 
dicha posibilidad. El deseo de ahorrar costes que sigue a la bancarrota de 1739 inclina a Campillo hacia una alternativa de gestión más económica para la Hacienda real: los resguardos se llevan al interior de las fronteras de Castilla y Aragón mientras se obliga a la Hacienda foral a administrar la renta por sí misma, comprometiéndola tan sólo a garantizar el abastecimiento de tabaco desde Sevilla y a no reparar en gastos en la lucha contra el fraude. Debemos admitir, además, la hipótesis de Hernández Escayola que destaca la influencia de Fermín de Goyeneche, asentista en la corte muy cercano al gobierno de Campillo, en la resolución del asunto y en el posterior manejo del estanco bajo control de las instituciones forales ${ }^{56}$.

La decisión adoptada había sido, de todos modos, motivo de disputa entre la Superintendencia de Hacienda, favorable a la medida, y la Dirección General de Rentas, contraria a la misma ${ }^{57}$. La muerte de Campillo en abril de 1743, junto con el inesperado descenso en la rentabilidad del estanco en Aragón y Castilla, motivó que Ensenada suspendiera la opción escogida por su antecesor. La decisión de volver a la fórmula anterior fue aplicada en mayo de 1744 y sancionada por las Cortes de 1743-1744 con la rúbrica de un nuevo contrato de cesión por el mismo valor que los anteriores ${ }^{58}$. La firmeza en la decisión de Ensenada se plasma en el diseño inmediato de una planta reforzada de empleados que incrementa el personal administrativo-contable de Pamplona hasta las sesenta personas y el de los miembros del resguardo por encima de las doscientas personas, para reemplazar al Ejército en funciones de vigilancia aduanera ${ }^{59}$.

Concluye así la reforma de la planta de la renta del Tabaco en Navarra que se mantendrá vigente hasta finales del siglo. Todos los objetivos de la corona habían sido alcanzados de modo satisfactorio ${ }^{60}$ : la Hacienda foral conservaba la teórica propiedad del monopolio y sus 87.529 reales anuales, pero la gestión administrativa

Una actuación no del todo desinteresada pues, en 1742, se le consignó el producto del tabaco adquirido por la diputación en los almacenes reales para el pago de deudas que con él mantenía la Real Hacienda (Hernández Escayola, 2001, pp. 123-124).

Especialmente por parte de Martín de Loynaz, defensor a ultranza de la aplicación de un sistema de administración directa que garantizase la oposición al contrabando. Zafra (1991), p. 109, señala que la publicación en 1740 de sus ideas fue la que convenció definitivamente al monarca de la conveniencia de aplicarlo en todos los casos.

El nuevo administrador sería José Antonio de Flon y Zurbarán, personaje muy vinculado al gobierno de Madrid por ser pariente del Administrador General del Tabaco, Jacobo de Flon y Zurbarán, (Hernández Escayola, 2001, p. 115).

El ámbito de actuación del resguardo tabaquero quedó dispuesto en las fronteras norte y oeste de Navarra, mientras las fronteras sur y este estarían vigiladas por guardas castellanos y aragoneses desde el otro lado. Dicho resguardo se unificará con el de aduanas, como en el conjunto de la Monarquía, que incorporará a esta misión cincuenta miembros asignados a la Ribera de Navarra. Véase Solbes (1999a), p. 17.

60 En 1752 Ensenada manifestó el deseo de terminar con la ficción de los arriendos pero el regente Pinto Miguel le convenció de lo contrario argumentando que el dinero abonado ya no suponía un porcentaje relevante sobre los ingresos obtenidos y que, caso de anular esta partida, habría que compensar de alguna manera a la hacienda foral. 
y el gobierno económico del estanco, junto con la capacidad para la lucha contra el fraude, quedaban definitivamente en manos de la Hacienda real; el déficit inicial, incrementado por la ampliación de la plantilla, tendió progresivamente a reducirse por el rápido incremento de los ingresos ${ }^{61}$.

¿Por qué resultó tan sencilla la intervención del gobierno central en este caso? Porque no se trató, a mi entender, de alterar la base fiscal de un impuesto de larga tradición histórica, sino de introducir directamente medidas de tipo administrativo para extraer el gobierno de la renta de Navarra y ponerlo en manos de la Superintendencia del Tabaco y de la Dirección General de Rentas para, a partir de entonces, actuar en consecuencia. Y es que este tipo de disposiciones sí eran "legales" en Navarra y la corona podía aplicarlas con entera libertad.

\subsection{Administración directa de la renta de Aduanas}

Ahora sabemos que, mientras las aduanas regresaban al sistema de arrendamiento en 1728, la lucha contra el fraude en Navarra se desplegaba desde las mayores posibilidades de actuación que ofrecía al gobierno central su control sobre el estanco tabaquero. Sin embargo, desde el inicio de la década de los cuarenta y especialmente con el gobierno de Ensenada, la introducción de la administración directa volvía a ser un objetivo inaplazable también para la renta de Tablas. La experiencia contrapuesta de los donativos y del estanco había mostrado a la administración central el camino de las reformas en Navarra que acabamos de expresar. Así, Ensenada iba a aparcar indefinidamente la cuestión del traslado fronterizo y la supresión del sistema aduanero navarro para centrarse en la aplicación de la administración directa con el objeto de desarrollar políticas coherentes con los intereses nacionales y trasladar su gobierno hasta la Superintendencia de Aduanas en detrimento de la Cámara de Comptos. En el año 1749 y dentro de un contexto nacional de imposición del modelo de gestión directa, se dispuso este nuevo sistema de gobierno sobre las aduanas navarras ${ }^{62}$.

Inmediatamente se produjo, a raíz de estas novedades, un conveniente proceso de unificación y simplificación de cargos de gobierno entre las rentas de aduanas y tabaco $^{63}$; un incremento de la plantilla de empleados del resguardo

\footnotetext{
61 Véase Solbes (1999a), pp. 21, 217 y 267, y García-Zúñiga (1994), pp. 136-137.

62 Real decreto 2/11/1748 (Solbes, 1999a, pp. 226-243).

63 García-Zúñiga (1993), p. 320; sobre la Instrucción Real de 23-XII-1748, véase Solbes (1999a), pp. 228-230. El regente del Consejo, Tomás Pinto Miguel, sería juez subdelegado de aduanas y juez conservador del tabaco; José Antonio de Flon y Zurbarán administrador de ambas rentas; Antonio de Flon y Sesma quedaría encargado del gobierno del resguardo unido.
} 
aduanero con cincuenta nuevos miembros; la publicación de un nuevo arancel para fijar contribuciones y cerrar posibilidades de acuerdo entre las partes ${ }^{64}$; todo ello de modo simultáneo a la consolidación de la perenne exacción por parte de la hacienda foral del nuevo impuesto sobre introducción de mercancías. La nueva política aduanera se vería reforzada, además, con la publicación de leyes complementarias que garantizaban el castigo de los contraventores según las leyes de Castilla o autorizaban a los guardas de los reinos fronterizos para entrar en el reino persiguiendo fraudes. La similitud entre el gobierno de las rentas de tabaco y aduanas no acaba aquí, pues la fórmula aplicada con el estanco para la dotación económica de su anterior gestor se utilizó también en este caso y, así, en lugar de decretar la desaparición del tribunal de Comptos, quedó dispuesta la remisión anual al mismo de 450.000 reales de vellón del producto de aduanas para la función del pago de salarios de empleados públicos que mantendría a su cargo.

La organización aduanera aplicada se mantuvo en esencia hasta el fin del siglo. Quedaba pendiente la cuestión de la integración de Navarra en el mercado nacional por medio del traslado, pero la política aplicada al respecto por el gobierno a partir de esta fecha se orientó sobre todo hacia la discriminación del comercio navarro de las ventajas que la política comercial nacional podía ofrecer a otros territorios dentro del contexto de apertura del mercado americano que sigue a los decretos de libre comercio. Se quería convencer de este modo a los naturales de las ventajas de una supresión voluntaria de sus fronteras, una sugerencia que fue, sin embargo, repetidamente rechazada por los navarros en las Cortes de 1757, en las de 1780-1781 y, de nuevo, en las de $1817-1818^{65}$.

64 El comercio de tránsito abonaría derechos de entrada del 3,33 por 100; las exportaciones de géneros propios hacia Castilla y Aragón, el 3 por 100 de su valor; las importaciones de géneros castellano-aragoneses que ya hubieran abonado derechos de salida, el 2 por 100; y la importación de productos extranjeros por mercaderes foráneos, el 5 por 100 establecido en las Ordenanzas. No podemos asegurar, de todos modos, que los administradores por cuenta de la Superintendencia no llegaran también a pactos puntuales con comerciantes extranjeros (Hernández Escayola, 2001, p. 114).

No disponemos de espacio para abordar la cuestión de las ventajas e inconvenientes del traslado o del desarrollo de los debates habidos en Cortes sobre la cuestión pero, en cualquier caso, se trata de uno de los temas que mayor atención ha recibido por parte de la historiografía. Un planteamiento general de la cuestión puede encontrarse en Barrenechea, Astigarraga y Lluch (1985), Oreja (1993) o Astigarraga (1996), pp. 72-88; el caso de 1757 puede encontrarse en Solbes (1996), pp. 701-727, el de 1780-1781 en Rodríguez Garraza (1974), pp. 97-132, Río Aldaz (1985), pp. 173-179 o Solbes (1996), pp. 854-879, y el caso de 1817-1818 en Río Aldaz (1985), pp. 179-185 y 242-331. El reciente II Simposio sobre libertad de comercio y aduanas en los territorios de Vasconia volvió a poner de manifiesto el interés por la cuestión (Notitia Vasconiae, 2003, pp. 129-190, 203-238 y 279-306). 


\section{A modo de conclusión: valoración de ingresos y gastos de la Hacienda real en Navarra (1740-1780)}

La principal premisa de este estudio se ha visto perfectamente sustentada con nuestro análisis: el reino de Navarra no experimentó con las reformas borbónicas ninguna transformación radical de sus bases fiscales, lo mismo que ocurre en los reinos de la Corona de Castilla y al contrario que en la Corona de Aragón, pero sí experimentó cambios significativos en relación con la práctica administrativa y de gestión de las rentas reales. La aplicación de la administración directa permitió detraer el gobierno económico de las rentas de Aduanas y Tabaco de Navarra, desde el tribunal de Comptos y la Hacienda foral respectivamente, para hacerlo depender de las Superintendencias Generales de Madrid. El recaudo del Servicio de Cortes, por el contrario, fue recayendo progresivamente en manos de unas instituciones forales que, a cambio, ofrecían una cierta rentabilidad a la corona adelantando su producto de contado. Los agentes fiscales, después incluso de la introducción de la administración directa, siguen siendo en la práctica las justicias municipales (donativos), el comercio mayorista (aduanas) y el minorista (tabaco), lo que propicia la pervivencia de la confusión entre lo público y lo privado.

La presión fiscal continuó basándose en fuentes indirectas organizadas a través de expedientes municipales, exacciones aduaneras o venta de determinados productos, con una única posible excepción del reparto por fuegos en los escasos lugares que recurrían efectivamente a un prorrateo entre los vecinos. El reducido incremento de la presión fiscal fue además repercutida sobre las haciendas municipales y especialmente sobre el cuerpo de comercio, que vivió la desaparición del "libre comercio" que había existido en Navarra de facto al quedar reducidos sus anteriores privilegios por vía impositiva (impuestos por introducción de mercancías, aplicación estricta de exacciones aduaneras y precio de venta de los tabacos) y por vía crediticia, con el adelantamiento obligado de gran parte de los caudales que el reino ofrecía como donativo.

Tan sólo resta estimar hasta qué punto resultaron remuneradoras para la corona el conjunto de novedades aplicadas durante este período, pues la administración directa implica un incremento de los gastos de gestión que hay que valorar en su justa medida, y establecer una relación con el conjunto de la Monarquía para observar si persiste o no un tratamiento fiscal relativamente privilegiado para los navarros. Con este fin, cabría realizar una somera estimación de las cantidades obtenidas por la Hacienda real en Navarra, publicadas y analizadas en estudios previos, para ponerlas en relación con las que disponemos para el conjunto de España. Un ejercicio que resulta factible para el período 1740-1780 y que exponemos a continuación. 


\section{CUADRO 1}

VALORACIÓN DE INGRESOS Y GASTOS OBTENIDOS POR RENTAS REALES EN NAVARRA, 1740-1780

(cantidades anuales medias en reales de vellón)

\begin{tabular}{|c|c|c|c|}
\hline \multirow{3}{*}{$\begin{array}{l}\text { Servicio de } \\
\text { Cortes }\end{array}$} & \multicolumn{2}{|l|}{ Valor entero } & 340.679 \\
\hline & \multicolumn{2}{|l|}{ Salarios y gastos } & 26.182 \\
\hline & \multicolumn{2}{|l|}{ Valor líquido (a Tesorería de Guerra) } & 314.497 \\
\hline & \multicolumn{2}{|l|}{ Gastos del Ejército en Navarra } & $i ?$ \\
\hline & \multicolumn{2}{|l|}{ Saldo } & ¿deficitario? \\
\hline & & $\begin{array}{c}\text { Arriendo } \\
(1740-1748)\end{array}$ & $\begin{array}{c}\text { Admon. directa } \\
(1749-1780)\end{array}$ \\
\hline & Valor entero & 475.000 & 650.000 \\
\hline & Salarios y gastos & 0 & 257.000 \\
\hline \multirow[t]{4}{*}{ Aduanas } & Valor líquido & 475.000 & 393.000 \\
\hline & Gastos de la Administración real (a Comptos) & 450.000 & 450.000 \\
\hline & Saldo & +25.000 & -57.000 \\
\hline & Valor entero & & 740.000 \\
\hline \multirow{3}{*}{ Tabaco } & Salarios y gastos & & 782.000 \\
\hline & Valor del arriendo (a la Hacienda foral) & & 87.529 \\
\hline & Valor líquido & & -129.529 \\
\hline
\end{tabular}

Fuentes: Datos de Solbes (1999a), pp. 17-22, y (2000), pp. 278 y 284-285, cotejados con García-Zúñiga (1994), pp. 82-139.

Los navarros otorgaron entre 1740 y 1780 cuatro donativos por valor de 14 millones de reales de vellón (incluido el de las Cortes de 1780-1781) que, descontados gastos de recaudo, entrarían prácticamente de contado en la tesorería general de Navarra para ser transferidos a la Tesorería de Guerra. Las cantidades medias son difíciles de estimar, como corresponde a un ingreso que no es regular, pero, hechas todas las salvedades, su valor líquido interanual podría situarse por encima de los 300.000 reales. Si comparamos esa cifra con los datos de Zafra y Angulo Teja sobre rentas provinciales en la Corona de Castilla, vemos que la provincia que menos contribuye es Zamora con una media cercana a los 800.000 reales anuales brutos y que Soria, la siguiente, ya ofrece cifras superiores al millón ${ }^{66}$. Con respecto a la Corona de Aragón basta con afirmar que los ingresos medios provenientes del equivalente valenciano remitidos a la tesorería del ejército de Valencia durante estos años superaron los 8 millones de reales de media anual $^{67}$. Hay que concluir por consiguiente que, pese al atractivo que supone el dinero 
ingresado de contado y de libre disposición para el Erario, los navarros soportan por este concepto una presión fiscal ridícula en comparación con el resto de España.

Los valores de la renta de Aduanas deben ser desagregados según el sistema de gestión aplicado: con la renta arrendada, el valor de los contratos firmados puede ser directamente consignado como ingresos líquidos mientras que, con la administración directa, debemos descontar del valor entero los gastos causados por una crecida planta de empleados. La conclusión es que los ingresos líquidos son superiores bajo la primera fórmula y, lo que es más importante, suficientes para atender el pago de los 450.000 reales en que se estima el gasto de la administración real en Navarra, lo que no sucede con la administración directa. El porcentaje que representan los ingresos líquidos obtenidos en Navarra durante el tiempo del arriendo sobre las cifras de García-Cuenca para rentas generales es superior al 2 por 100 del total nacional $^{68}$; con la administración directa el valor entero de la renta navarra desciende hasta el 1,3 por $100 \mathrm{y}$, como los gastos asumidos se elevan hasta el 4 por 100 del total nacional, la importancia relativa del valor líquido de la renta cae incluso por debajo del 1 por 100. Así, podemos estimar que la aplicación de la administración directa se tradujo en Navarra en un crecimiento de los valores inferior al del conjunto de la Monarquía, una pérdida de rentabilidad y unos rendimientos netos insuficientes para acudir a las obligaciones consignadas sobre la renta.

La reforma sobre el Tabaco coincide a grandes rasgos con la norma centralizadora aplicada en toda la Monarquía y convierte a Navarra en una administración provincial más dentro del ámbito del estanco. Su talante peculiar se refiere exclusivamente a un coste más elevado que el de otras administraciones como consecuencia de la oposición a un activo contrabando que obliga al establecimiento de una planta de empleados muy amplia que se traduce, pese a un incremento continuado de los consumos legales y sus valores enteros, en un déficit permanente en los valores líquidos de la renta; de hecho, es la única administración provincial del tabaco deficitaria en toda España. Su porcentaje de ingresos brutos representa el 0,8 por 100 del total nacional (por encima de Ávila, Cuenca, Logroño o Soria), pero la media del gasto soportado supone el 5,4 por 100 del total (por debajo tan sólo de administraciones tan significativas como Sevilla, Valencia, Galicia o Cádiz) ${ }^{69}$. Estas cifras representan el sacrificio de los ingresos del estanco en Navarra en aras de una reducción del contrabando beneficiosa para el conjunto del estanco general.

En conclusión, la contribución por Servicios de Cortes como alternativa del sistema de rentas provinciales encarna durante todo el siglo XVIII la esencia del privilegiado tratamiento fiscal de los navarros, mientras que las reformas administrativas aplicadas sobre Aduanas y Tabaco transformaron ambas rentas en expedientes per-

\footnotetext{
$68 \quad$ García-Cuenca (1983), p. 259.

69 Datos de GRETA (2002), pp. 316-318.
} 
fectamente integrados dentro del esquema centralizador implantado por la monarquía borbónica. Estas últimas ofrecen rendimientos que podemos calificar de normales, en relación con el volumen de población y riqueza del territorio, aunque la introducción de un mayor control administrativo y de resguardo determinase el sacrificio permanente de los caudales ingresados. Los ingresos del tabaco mantienen el resguardo fronterizo, los de aduanas la administración real y los del donativo el ejército, pero los tres presentan al fin y al cabo la característica común de ser sistemáticamente deficitarios, lo que explica la necesidad de compensarlos mediante el envío de remesas de dinero desde otras regiones ${ }^{70}$.

La constatación de esta última realidad es una buena manera de concluir nuestro trabajo, pues contribuye a mostrar las razones del fracaso a largo plazo de las reformas borbónicas en su firme deseo de sanear las finanzas del Estado.

\section{Bibliografía}

ANGULO MORALES, Alberto (1999): “Estanco y contrabando de tabaco en el País Vasco (1684-1876)", en GONZÁLEZ ENCISO, Agustín, y TORRES SÁNCHEZ, Rafael (eds.), Tabaco y economía en el siglo XVIII, Pamplona, EUNSA, pp. 195-237.

ANGULO TEJA, Carmen (2002): “Los ingresos y gastos procedentes de las Rentas Provinciales, 1768-1784", Revista de Historia Económica, XX, 3, pp. 479-507.

ARTOLA, Miguel (1978): "La Hacienda Real de Navarra en el Antiguo Régimen", Hacienda Pública Española, 55, pp. 131-146.

-(1982): La Hacienda del Antiguo Régimen, Madrid, Alianza Editorial.

ASTIGARRAGA, Jesús (1996): Ilustración y economía en Navarra (1770-1793): el pensamiento económico de José $M^{a}$ Magallón y Francisco Javier de Argaiz, Clásicos del Pensamiento Económico Vasco, tomo III, Vitoria, Gobierno Vasco.

AZCONA GUERRA, Ana (1996): Comercio y comerciantes en la Navarra del siglo XVIII, Pamplona, Gobierno de Navarra.

BARRENECHEA, José M., ASTIGARRAGA, Jesús, y LLUCH, Ernest (1985): “Valentín de Foronda en Navarra y el proyecto de traslación de aduanas de Berriechea y Zarigaiz (1781)", Príncipe de Viana, I Congreso de Historia de Navarra de los siglos XVIII, XIX y XX, tomo I, pp. 203-216.

BERNABÉ GIL, David (1993): “La fiscalidad de los territorios peninsulares de la Corona de Aragón durante la época de los Austrias", en FORTEA, José I., y CREMADES, Carmen $\mathrm{M}^{\mathrm{a}}$ (eds.), Fiscalidad y Hacienda en el Antiguo Régimen, Murcia, Universidad de Murcia, pp. 15-31.

70 Remesas percibidas con concepto de aduanas y tabaco en García-Zúñiga (1994), pp. 95 y 139-140. 
BIBILONI AMENGUAL, Andreu (2000): Contrabandistes i agents de rendes. Supervivens $i$ acumuladors en torn al negoci del tabac a Mallorca durant els segles XVII i XVIII, Mallorca, El Tall.

BILBAO, Luis María (1984): “La fiscalidad de las Provincias Exentas de Vizcaya y Guipúzcoa durante el siglo XVIII", en ARTOLA, Miguel, y BILBAO, Luis Ma (eds.), Estudios de Hacienda: de Ensenada a Mon, Madrid, IEF, Monografía 35, pp. 67-83.

-(1991): "Haciendas Forales y Hacienda de la Monarquía. El caso vasco, siglos XIVXVIII", Hacienda Pública Española, Monografía 1, Historia de la Hacienda en España (s. XVI-XX). Homenaje a Don Felipe Ruiz Martín, pp. 43-58.

COMÍN, Francisco (1991): "Los monopolios fiscales", COMÍN, Francisco, y MARTÍN ACEÑA, Pablo (dirs.), Historia de la empresa pública en España, Madrid, EspasaCalpe, pp. 139-175.

COMÍN, Francisco y MARTÍN ACEÑA, Pablo (1999): Tabacalera y el Estanco del Tabaco en España, 1636-1998, Madrid, Tabapress.

ESCOBEDO ROMERO, Rafael (2004): El monopolio fiscal del tabaco en la España Moder$n a$, tesis doctoral inédita, Universidad de Navarra.

FERNÁNDEZ ALBADALEJO, Pablo (1977): “El decreto de suspensión de pagos de 1739: análisis e implicaciones", Moneda y Crédito, 140-143, pp. 51-85.

FERNÁNDEZ DE PINEDO, Emiliano (1984): “Los ingresos de la Hacienda Real en Cataluña (1717-1779)”, ARTOLA, Miguel, y BILBAO, Luis Ma (eds.), Estudios de Hacienda: de Ensenada a Mon, Madrid, IEF, Monografía 35, pp. 193-207.

-(1991): "Gasto público y reformas fiscales. Las Haciendas forales vascas", Hacienda Pública Española, Monografía 1, Historia de la Hacienda en España (s. XVI-XX). Homenaje a Don Felipe Ruiz Martín, pp. 93-100.

FONTANA LÁZARO, Josep (1980): La Hacienda en la Historia de España, 1700-1913, Madrid, IEF.

FRANCH BENAVENT, Ricardo, y GIMÉNEZ CHORNET, Vicent (2003): “Una aproximación a la gestión territorial de la Real Hacienda: las cuentas del Tesoro del Ejército de Valencia (1751-1807)", en Estudis. Revista de Historia Moderna, 29, pp. 105-129.

GARCIA-CUENCA ARIATI, Tomás (1983): “Las Rentas Generales o de aduanas de 1740 a 1774", ANES, Gonzalo, ROJO, Luis A., y TEDDE, Pedro (eds.), Historia económica y pensamiento social. Estudios en homenaje a Diego Mateo del Corral, Madrid, Alianza-Banco de España, pp. 237-262.

-(1991): "El sistema impositivo y las rentas generales o de Aduanas en España en el siglo XVIII", Hacienda Pública Española, Monografía 1, Historia de la Hacienda en España (s. XVI-XX). Homenaje a Don Felipe Ruiz Martín, pp. 59-71.

GARCÍA-ZÚÑIGA, Mario (1992): “Orígenes, evolución y crisis de una Hacienda Foral: Navarra, 1642-1820", Boletín del Instituto Gerónimo de Uztáriz, 6, pp. 5-24.

-(1993): "Haciendas forales y reformas borbónicas. Navarra, 1700-1808", Revista de Historia Económica, XVI, 2, pp. 307-334.

-(1994): Estadísticas históricas de Navarra. Hacienda, población y precios (siglos XVIXVIII), Pamplona, Gobierno de Navarra. 
GARCÍA-ZÚÑIGA, Mario, MUGARTEGUI, Isabel, y TORRE, Joseba de la (1991): "Evolución de la carga tributaria en la España del Setecientos", Hacienda Pública Española, Monografía 1, Historia de la Hacienda en España (s. XVI-XX). Homenaje a Don Felipe Ruiz Martín, pp. 81-91.

GARCÍA TROBAT, Pilar (1999): El equivalente de Alcabalas, un nuevo impuesto en el Reino de Valencia durante el XVIII, Valencia, Generalitat Valenciana.

GONZÁLEZ ENCISO, Agustín (1988): “Organización y valores de la renta del Tabaco en la primera mitad del siglo XVIII", CREMADES, Carmen $\mathrm{M}^{\mathrm{a}}$ (ed.), Actas del I Symposium Internacional: Estado y fiscalidad en el Antiguo Régimen, Murcia, Universidad de Murcia, pp. 259-277.

-(2003): Felipe V: La renovación de España. Sociedad y economía en el reinado del primer Borbón, Pamplona, EUNSA.

GONZÁLEZ ENCISO, Agustín, y TORRES SÁNCHEZ, Rafael (eds.) (1999): Tabaco y Economía en el siglo XVIII, Pamplona, EUNSA.

GORDO ASTRÁIN, Óscar (1993): “La aportación de los municipios navarros a la Real Hacienda en el siglo XVIII", FORTEA, José I., y CREMADES, Carmen M ${ }^{\mathrm{a}}$ (eds.), Fiscalidad y Hacienda en el Antiguo Régimen, Murcia, Universidad de Murcia, pp. 313-321. GRETA (GRUPO DE ESTUdiOS DEL TABACO) (2002): “El consumo de tabaco en España en el siglo XVIII", Cuadernos de Investigación Histórica, 19, pp. 313-345.

HERNÁNDEZ, B. (2003): “Els segles XVI i XVII a la Corona d'Aragó. Desenvolupament fiscal del regne i integració financiera en la Monarquía Hispánica", Estudis. Revista de Historia Moderna, 29, pp. 65-80.

HERNÁNDEZ ESCAYOLA, Ma Concepción (2001): Negocio y servicio: finanzas públicas y hombres de negocios en Navarra en la primera mitad del siglo XVIII, tesis doctoral inédita, Universidad de Navarra.

KAMEN, Henry (1974): La Guerra de Sucesión en España, Barcelona, Grijalbo.

LUXÁN, Santiago, SOLBES, Sergio, y LAFORET, Juan J. (eds.) (2000): El mercado del tabaco en España durante el siglo XVIII, Las Palmas de Gran Canaria, Fundación Altadis y Universidad de Las Palmas.

MERINO NAVARRO, José P. (1987): Las cuentas de la administración central española, 1750-1820, Madrid, IEF.

MUGARTEGUI EGUÍA, Isabel (1990): Hacienda y fiscalidad en Guipúzcoa durante el Antiguo Régimen, 1700-1814, San Sebastián, Fundación Cultural Caja de Guipúzcoa.

Notitia Vasconiae: Revista de Derecho Histórico de Vasconia, 2 (2003), San Sebastián, Instituto de Derecho Histórico de Vasconia.

OREJA RETA, J. Ma (1993): “El reformismo borbónico y la política aduanera en Navarra: los intentos de traslación de aduanas de 1717, 1757 y 1780", FORTEA, José I., y CREMADES, Carmen $\mathrm{M}^{\mathrm{a}}$ (eds.), Fiscalidad y Hacienda en el Antiguo Régimen, Murcia, Universidad de Murcia.

PIEPER, Renate (1992): La Hacienda Real bajo Fernando VI y Carlos III (1753-1788): repercusiones económicas y sociales, Madrid, IEF. 
REY CASTELAO, Ofelia (2004): "Los estudios sobre fiscalidad en la Época Moderna", en XV Coloquio de Historia Canario-Americana, Las Palmas de Gran Canaria, Cabildo Insular, pp. 1.400-1.435.

RÍO ALDAZ, Ramón del (1985): Las últimas Cortes del reino de Navarra (1828-29), San Sebastián, Haramburu.

-(1992): "Los antecedentes de la reforma fiscal burguesa en Navarra: los últimos años del donativo (1817-1834)", Boletín del Instituto Gerónimo de Uztáriz, 5, pp. 5-27.

RODRÍGUEZ GARRAZA, Rodrigo (1974): Tensiones de Navarra con la administración central (1778-1808), Pamplona, Diputación Foral-CSIC.

RODRÍGUEZ GORDILLO, José M. (2002a): La creación del estanco del tabaco en España, Madrid, Fundación Altadis.

-(2002b): La difusión del tabaco en España. Diez estudios, Sevilla, Fundación Altadis y Universidad de Sevilla.

SALCEDO IZU, Joaquín (1981): “El sistema fiscal navarro en la Cámara de Comptos Reales", Príncipe de Viana, 163, pp. 617-640.

SOLBES FERRI, Sergio (1996), La Real Hacienda en el Reino de Navarra (1700-1781), tesis doctoral, Pamplona, Universidad de Navarra.

-(1999a): Rentas reales de Navarra: proyectos reformistas y evolución económica (17011765), Pamplona, Gobierno de Navarra.

- (1999b): “El arriendo de la renta del Tabaco a través de la Real Hacienda: una eficaz fórmula de intervencionismo regio en Navarra (1717-1749)", en GONZÁLEZ ENCISO, Agustín, y TORRES SÁNCHEZ, Rafael (eds.), Tabaco y Economía en el siglo XVIII, Pamplona, EUNSA, pp. 319-352.

-(2000): "Distribución y consumo legal de tabacos en Navarra: 1731-1779", en LUXÁN, Santiago, SOLBES, Sergio, y LAFORET, Juan J. (eds.), El mercado del tabaco en España durante el siglo XVIII, Las Palmas de Gran Canaria, Fundación Altadis y Universidad de Las Palmas, pp. 245-285.

TORRE, Joseba de la (1993): "El recurso al crédito en las Haciendas municipales navarras (1750-1850)", en FORTEA PÉREZ, José I., y CREMADES GRIÑÁN, Carmen $\mathrm{M}^{\mathrm{a}}$ (eds.), Fiscalidad y Hacienda en el Antiguo Régimen, Murcia, Universidad de Murcia, pp. 603-614.

TORRE, Joseba de la y GARCÍA-ZÚÑIGA, Mario (1998): "Hacienda foral y crecimiento económico en Navarra durante el siglo XIX", en TORRE, Joseba de la, y GARCÍA-ZÚÑ̃IGA, Mario (eds.): Hacienda y crecimiento económico. La reforma de Mon, 150 años después, Madrid, Gobierno de Navarra-Marcial Pons.

VÁZQUEZ DE PRADA, Valentín, USUNÁRIZ, Jesús Mª GARCÍA BOURRELLIER, Rocío, MARTINEZ ARCE, Ma Dolores, y SOLBES FERRI, Sergio (1993): Las Cortes de Navarra desde su incorporación a la Corona de Castilla: tres siglos de actividad legislativa, Pamplona, EUNSA.

ZAFRA OTEIZA, Juan (1991): Fiscalidad y Antiguo Régimen. Las rentas provinciales del reino de Granada (1746-1780), Madrid, Junta de Andalucía e IEF. 